\section{RBM3 EXPRESSION IN NEONATES WITH PONTOSUBICULAR NEURON} NECROSIS

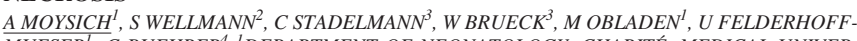
MUESER ${ }^{I}, C$ BUEHRER ${ }^{4}$ I DEPARTMENT OF NEONATOLOGY, CHARITÉ, MEDICAL UNIVERSITY OF BERLIN (GERMANY), ${ }^{2}$ DEPARTMENT OF PEDIATRIC ONCOLOGY AND HEMATOL OGY, CHARITÉ, MEDICAL UNIVERSITY OF BERLIN (GERMANY), ${ }^{3}$ INSTITUTE OF NEUROPATHOLOGY, GEORG-AUGUST-UNIVERSITY (GERMANY), ${ }^{4}$ UNIVERSITY CHILDREN'S HOSPITAL (SWITZERLAND)

Objective: Pontosubicular neuron necrosis (PSN) represents an age-specific response to severe hypoxic-ischemic injury (HII) occurring in human neonates but not in older children or adults. Histologically, PSN is characterised by acute neuronal death in the pontine nuclei and the hippocampa subiculum bearing the hallmarks of apoptosis. The expression of Rbm3, a glycine-rich RNA-binding protein, is enhanced under hypoxic conditions and independent of HIF (hypoxia inducible factor). It is well known, that proteins which are dependant on HIF, e.g. Erythropoetin play an important role in HII. This study aims to determine whether the HIF-independent activation of Rbm3 is also a significant factor in the pathogenesis of PSN. Methods: We have investigated the expression of Rbm3 in human autopsy material consisting of 12 PSN cases and 10 age-matched controls without PSN. Immunohistochemistry and double labeling for Rbm3 and the astrocyte marker glial fibrillary acid protein (GFAP), the microglia/macrophage specific marker KiM1P and the neuronal marker NeuN was performed on formalin-fixed, paraffin-embedded brain specimens.

Results: In PSN cases and controls, mainly neuronal cells expressed Rbm3. The number of immunopositive cells was significantly increased $(p=0.001)$ in PSN cases. Predominantly degenerating cells with signs of later apoptotic stages showed Rbm3 expression. In earlier stages of apoptosis immunopositivity for Rbm3 was increased compared to contols, but less prominent.

Conclusion: In addition to HIF-dependant proteins, the induction of the HIF-independent protein RMB3 is observed in response to human hypoxic-ischemic injury.
COMPARING TWO METHODS OF FEEDING IN VERY LOW BIRTH WEIGHT PREMATURE NEWBORNS

F NAVAEI, L MORADI IISFAHAN UNIVERSITY OF MEDICAL SCIENCE,ISFAHAN,IRAN , ${ }^{2}$ ISFAHAN UNIVERSITY OF MEDICAL SCIENCE,ISFAHAN, (IRAN)

Background:Neonates with less than 32-34 weeks of gestation are prone to feeding intolerance and Necrotizing Entrocolitis (NEC).Different methods for feeding have been used in the world and several studies have been made to evaluate the outcomes of these methods.

Objective:To compare two methods of feeding of very low birth weight(VLBW premature neonates in two hospitals(both affiliated to Iran,Isfahan University of Medical Sciences)and to evaluate the effects of these methods on feeding tolerance as well as risk of NEC.

Methods:this prospective case-control Analytic study was performed on 68 healthy premature neonates in each hospitals(that we said above) in 2003.In method which we used in Behesht hospital(No.1 method),feeding initiated with $2-3 \mathrm{ml}$ of breast milk every $2 \mathrm{hr}$ and advanced daily $15-25 \mathrm{ml} / \mathrm{kg}$. In method which we used in Alzahra hospital(No.2 method),feeding initiated with 1-2 $\mathrm{ml}$ of breast milk every $1 \mathrm{hr}$. and advanced daily $1 \mathrm{ml}$ to each feeding ,until $150 \mathrm{ml} / \mathrm{kg} / 24 \mathrm{hr}$. We filled a checklist of feeding method,feeding intolerance,NEC and analysed them at $\mathrm{P}<0.05$ with SPSS9 software using the t- test. Results:In 48 cases $(35.2 \%)$ developed feeding intolerance( 20 in No.1 and 28 in No. 2 method, $\mathrm{P}>0.05)$.In one case of No.1 method and two cases in No. 2 method, NEC occured $(\mathrm{P}=0.559)$.

Discussion and conclusion:The rate of feeding intolerance in our study was lower than other centers and in No.1 method was lower than No. 2 method .This Probably is due to longer feeding intervals.NEC incidence in our study was lower Than other similar studies and in No.1 method(1.47\%) less than No. 2 method $(2.9 \%)$ But these results are not significant in view of analysis, therefore we found that in different methods the main principle in feeding of premature neonates is to proceed cautiously and gradually.

Key words:premature neonate,very low birth weight,Nutrition,Necrotizing Entrocolitis.

\section{0}

NEONATAL DIFFUSION TENSOR IMAGING OF THE BRAIN AT 3 TESLA MJ MIRANDA ${ }^{1,2}$, L HANSON ${ }^{l}, P$ BORN ${ }^{l}, Z$ ZNAGY ${ }^{3,4}{ }^{l}$ DANISH RESEARCH CENTRE FOR MAGNETIC RESONANCE, COPENHAGEN UNIVERSITY HOSPITAL, HVIDOVRE, (DENMARK), ${ }^{2} D E-$ PARTMENT OF PEDIATRICS, COPENHAGEN UNIVERSITY HOSPITAL, HVIDOVRE, (DENMARK), ${ }^{3}$ DEPARTMENT OF WOMAN AND CHILD HEALTH, NEONATAL UNIT, KAROLINSKA INSTITUTE, STOCKHOLM (SWEDEN), ${ }^{4}$ DEPARTMENT OF HOSPITAL PHYSICS, MRI UNIT AT THE KAROLINSKA UNIVERSITY HOSPITAL, STOCKHOLM, (SWEDEN)

In magnetic resonance imaging (MRI) the trend is to move towards higher magnetic field strengths. This tendency is driven by the possibility to obtain better signal to noise ratios. One recent development is diffusion tensor imaging (DTI). As water diffusion is less hindered along the length of the axon than its cross section DTI allows for the investigation of the white matter microstructure. For example such histological correlates as the size cross sectional density, organization of axons and degree of myelination can be studied with this method. 13 preterm infants at term equivalent age and 6 healthy term newborn controls were studied. Median GA in the preterm group was 31 weeks, median postmenstrual age $(\mathrm{PMA})=41$ weeks when MR was performed. Term controls were examined at a median postnatal age of 2 days. Each subject underwent a single MRI examination on a 3 Tesla Trio Siemens scanner. MR protocol included a DTI sequence with 6 non-collinear diffusion weighting directions. From the raw data a diffusion tensor was estimated with linear least square fitting and from the tensor a scalar measure of anisotropic diffusion was calculated. This measure, called fractional anisotropy (FA), has been used to compare the groups. We present results demonstrating the feasibility of DTI at 3 Tesla in neonatal subjects. We found Anisotropy values which were not significantly different between preterm infants at term-equivalent age and healthy term controls in Corpus callosum splenium and White matter. However, values in the posterior limb of internal capsule (PLIC) were significantly higher for the preterm group $(\mathrm{p}=0.0017)$

Conclusions: Diffusion tensor imaging of neonatal subjects can be safely carried out with high quality results on 3 Tesla. Anisotropy values in PLIC are significantly higher for preterm infants at term-equivalent age as compared with term control infants in the studied group.

\section{1}

\section{SIMILARSERUM TRANSFERRIN RECEPTOR IN PRETERM COMPARED WITH TERM NEWBORNS: FETAL ERYTHROPOIESIS IS MAINTAINED IN PRETERMS DESPITE LIMITED IRON SUPPLY}

R NAMGUNG ${ }^{l}$,CH OH ${ }^{l}, M S$ PARK ${ }^{l}, C$ LEE I YONSEI UNIVERSITY COLLEGE OF MEDICINE (SOUTH KOREA)

Background/Aim: Serum transferrin receptor(STfR), a marker of iron status and erythropoiesis, correlates directly with erythropoietic activity and inversely with the amount of iron. In newborns, cord sTfR may or may not be influenced by maturity: positive correlations or no relation between sTfR and gestation have been reported. Male term neonates have been reported to have higher or similar sTfR than female term newborns. We purport to determine whether cord serum STfR and iron indices are influenced by maturity or by gender. We hypothesized that preterm newborns would have lower sTfR than term newborns, possibly related to limited fetal iron supply, and gender difference in fetal erythropoiesis is present in preterms.

Methods: Cord serum sTfR, iron, and ferritin concentrations were analyzed in 37 preterm and 60 term newborns (gestation $32.3 ; 3 / 41.1 \mathrm{vs} 39.2 ; 3 / 40.3 \mathrm{wks}$; birth weight $2.09 ; 3 / 41.1 \mathrm{vs} 3.3 ; 3 / 40.4 \mathrm{~kg}$ ). In preterm, 17 were males, and 20 females; in term, 28 males and 32 females. Results: In preterm vs term newborns, cord serum sTfR was similar(33.2;3/4 $14.2 \mathrm{vs} 28.7 ; 3 / 41.5 \mathrm{ng} / \mathrm{ml}, \mathrm{p}=0.23)$, cord serum iron was significantly lower $(95.4 ; 3 / 462.5$ vs $175 ; 3 / 459.3 \mathrm{~g} / \mathrm{dL}, \mathrm{p}<0.001)$, cord serum ferritin wa higher (194.6;3/4 130.5 vs $155.7 ; 3 / 495.1 \mathrm{~g} / \mathrm{dL}, \mathrm{p}<0.01)$, and reticulocytes were higher $(4.4 ; 3 / 41.7$ vs $2.8 ; 3 / 41.5 \%, \mathrm{p}<0.01)$, whereas hemoglobin was not different between groups $(15.7 ; 3 / 41.4$ vs $15: 3 / 41.2, p=0.07)$. Cord serum $s$ TfR was not different by gender, either in preterm or term infants. Cord serum iron correlated positively with gestation $(r=0.396, p<0.01)$. Cord serum sTfR correlated positively with cord hemoglobin $(\mathrm{r}=0.414, \mathrm{p}<0.001)$, but not with cord iron, ferritin or reticulocytes. Conclusions: Thus, cord serum sTfR was not influenced by maturity or by gender; and indices of iron status were influenced by maturity, but not by gender. Since sTfR reflects fetal erythropoietic activity, we speculate that fetal erythropoiesis in preterm newborns may be maintained despite relative limited iron availability.

\section{3}

A REGULARITY-BASED SEIZURE DETECTION ALGORITHM FOR NEONATES

MA NAVAKATIKYAN $\stackrel{1,5}{\text {, }}$ PB COLDITZ ${ }^{2}$, CJ BURKE ${ }^{3}$, TE INDER ${ }^{4}$, J RICHMOND ${ }^{3}$, CE WILLIAMS $^{5}$ ${ }^{T}$ BRAINZ INSTRUMENTS LIMITED (NEW ZEALAND) ${ }^{2}$ ROYAL BRISBANE AND WOMEN'S HOSPITAL (NEW ZEALAND), ${ }^{3}$ ROYAL CHILDREN'S HOSPITAL (NEW ZEALAND), ${ }^{4}$ ROYAL CHIL DREN'S HOSPITAL (AUSTRIA), ${ }^{5}$ LIGGINS INSTITUTE, UNIVERSITY OF AUCKLAND

Background: Continuous EEG recordings in neonates are valuable both for monitoring of seizures and to measure response to therapy. Impediments to robust seizure detection include large datasets, limite availability of expert neurologist interpretation, the presence of low amplitude seizures and short seizures. Methods used to date in automatic seizure detection include Harmonie with Sensa software (Stellate Inc. Canada) based on Gotman et al (1997) algorithm.

Objective: We evaluate a new approach to automated seizure detection (BrainZ Instruments Ltd., New Zealand) based predominantly on the assessment of relatively prolonged regularity in EEG waves Design/Methods: The algorithm consists of the decomposition of EEG into adjacent waves and analysis of their regularity. Interval, amplitude and shape information were used in this regularity analysis Conservative and liberal assessments (similar to integral-overlap and any-overlap, Wilson et al, 2003) of algorithm sensitivity and positive predictive value (PPV) were based on detected seizure duration. The 作 52 multi channel EEG recordings of neonates totalling 20 hours, selected for the purpose of challenging the algorithm. The dataset included 14 EEG recordings with 81 seizures, 22 EEG recordings of normal patients with artefacts and 16 recordings of abnormal EEG.

Results: For the BrainZ algorithm the conservative and liberal assessment of performance showed sensitivity of 83 and $95 \%$ and PPV of 52 and $75 \%$, respectively. There were 1.8 false positive detection per hour. In comparison, the Sensa software (version 5.4) had sensitivity 37 and $85 \%$ and PPV 45 and $48 \%$, respectively; with 11.7 false positives per hour.

Conclusions: The regularity-based algorithm performed well and provides a basis for major improvements in neonatal seizure detection.

References:

1 Gotman J, Flanagan D, Zhang J, Rosenblatt B. Electroenceph. Clin. Neurophysiol. 1997; 103 (3): $356-62$.

2. Wilson SB, Scheuer ML, Plummer C, Young B, Pacia S. Clin. Neurophysiol. 2003; 114 (11): 2156-64

\section{4}

THE ROLE OF SALIVARY ANTI-TRANSGLUTAMINASE AUTOANTIBODIES AT THE DIAGNOSIS AND FOLLOW-UP OF COELIAC DISEASE

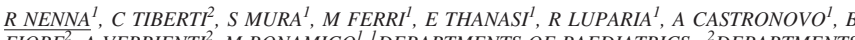
FIORE ${ }^{2}$, A VERRIENTI ${ }^{2}, M$ BONAMICO ${ }^{l}$ DEPARTMENTS OF PAEDIATRICS,${ }^{2}$ DEPARTMENTS OF CLINICAL SCIENCES (ITALY)

Aim: We have demonstrated that saliva can be used to screen coeliac disease (CD) children (J Pediatr 2004). The aim of this study was to evaluate salivary tTGAb presence on a large series of $\mathrm{CD}$ patients at diagnosis and during the follow-up.

Methods: 77 coeliacs at the first biopsy (Group 1a: $25 \mathrm{~m} ; 1.9-28$ yrs), 35 of them on a gluten-free diet (GFD) from at least 6 months (Group $1 \mathrm{~b}: 10 \mathrm{~m}, 2.3-26.6 \mathrm{yrs}$ ), 74 gastroenterological controls (Group 2: 35m; 1.3-18 yrs) and 40 healthy controls (Group 3: 11m; 21.9-41.5 yrs) were enrolled in this study. IgA-tTGAb presence on serum and saliva of each subject were detected with a fluid-phase radioimmunoprecipitation method. The ROC analysis was used to detect the limit of positivity of tTGAb method. IgA-EMA were tested by the indirect immunofluorescence.

Results: The percentages of salivary and serum tTGAb and EMA positivity were in Group $1 \mathrm{a}$ $96.1 \%, 98.7 \%$ and $90.9 \%$ respectively, and in Group $1 \mathrm{~b} 60 \%, 65.7 \%$ and $36.7 \%$ respectively. Mean salivary or serum tTGAb indexes \pm SD were significantly lower in Group $1 \mathrm{~b}(0.12 \pm 0.16$ and $0.21 \pm 0.29$ respectively) than in Group $1 \mathrm{a}(0.40 \pm 0.40$ and $0.77 \pm 0.33$ respectively) with a $\mathrm{p}<0.0001$. All control subjects were found tTGAb and EMA negative, both in saliva and serum.

Conclusion: This study confirms the possibility of salivary tTGAb detection in CD patients with a high sensitivity also during follow-up. The sensitivity of the salivary and serum Ab detection in patients on a GFD appears to be comparable. Salivary tTGAb presence in these subjects could reveal a non strict adherence to the diet with possible nutritional and immunological implications. 